\title{
Editorials
}

\section{Creating a holistic support service for people with vision impairment}

The diagnosis of visual impairment is life changing for patients as it has huge impacts on activities and tasks of daily living, selfidentity, and mental wellbeing. In order to adapt to living with visual impairment, a multidimensional, holistic service is required in terms of practical, social, and emotional support and rehabilitation in order to empower people to become independent. ${ }^{1}$

\section{THE IDEAL SUPPORT SERVICE}

The mental health needs of people with visual impairment, and in fact chronic diseases in general, are an important aspect that needs to be addressed as part of a holistic service. The Living Better Project, ${ }^{2}$ a Scottish Government-funded initiative in 2008, identified five key types of support that patients with chronic diseases desired:

- emotional support - receiving empathy and understanding from others;

- informational support - understanding the illness, and how to access resources and learn coping strategies in order to self-manage;

- assistance and practical support transport and services to help patients be socially active and pursue activities:

- peer support - the opportunity to share experiences and information with peers for empathy and knowledge; and

- South Asians with diabetes and CHD desired bilingual, religiously appropriate, and gender-sensitive local support services.

The above themes are the same for patients with visual impairment and many of these findings have been reflected in research specific to visual impairment. Specifically, patients with visual impairment have expressed a need for more emotional support and counselling, to gain skills regarding independent living and maintenance of employment as well as communication techniques such as braille and equipment provision, alongside practical support. They also suggested that their partners and significant others should be trained in how to allow a visually impaired person space to become independent rather than to constantly 'do things for them."

Fundamentally, a patient-centred

"The rehabilitation workers felt that there was a lack of recognition for their specialist skills in vision rehabilitation by other health professionals, which could underlie the delay in referrals.

approach is key and a successful programme must be tailored to a particular patient's needs and what they want to obtain from rehabilitation. People cope with vision loss differently so it is also important not to limit patients to a certain timescale and to start rehabilitation as soon as possible, as interest and motivation can be lost if rehabilitation occurs too long after initial sight loss.

\section{CURRENT VISION REHABILITATION IN THE UK}

Local rehabilitation services for people with visual impairment in the UK can be inconsistent in terms of geographical availability, model of service delivery, duration, and content of rehabilitation programmes. ${ }^{3}$ A survey of local authorities with adult social care responsibilities was conducted regarding service provision for people with visual impairment. ${ }^{1}$ Out of 152 there were 87 local authorities that responded. Results of the survey found that, although there are areas in service provision that need improving, many areas have been addressed fairly well. All services that responded provided information and signposting. Most services offered independent living skills, orientation, mobility, and training in use of aids and equipment. Almostall responders described their services as being open-ended, with the patient dictating how long they used their services for. Despite many of the initial referrals not being screened by a specialist, the majority of actual assessments (95\%) were carried out by a specialist.

Areas that services performed less well in included consistency of services available, emotional support, and specialist input. Self-management courses were only available from just over a third of respondents. Of the services, 19\% did not have a specialist who delivered the rehabilitation. Counselling was only offered by $24 \%$ of services and $21 \%$ did not offer any emotional support for patients, partners, or carers.

As only $57 \%$ of local authorities responded, it must be taken into account that there is a potential for bias and that only local authorities with favourable data completed the survey, or that particularly holistic services have been missed. It is also difficult to analyse the effectiveness of the services provided as measures of outcome were not often used by local authorities and, even when used, the measurement tools were not always standardised. ${ }^{1}$

\section{BARRIERS TO THE IDEAL SERVICE}

Even with the knowledge of the key aspects of an ideal support service for visually impaired people, the actual delivery of such a service is difficult. A discussion group with vision rehabilitation workers reported difficulties with time pressure, inadequate training, and difficulty collaborating with some external teams. ${ }^{1}$ They felt that delays in referral meant that patients could become entrenched in their current way of living so were less motivated to become more independent. Delays could occur if the patient has not been referred soon enough or simply if the patient has not been made aware of the service in the first place. The rehabilitation workers felt that there was a lack of recognition for their specialist skills in vision rehabilitation by other health professionals, which could underlie the delay in referrals.

Other barriers include practical difficulties for patients in terms of transport, time, and commitment. A person's perception of support and rehabilitation was another factor as people are less likely to participate in such services if they believe they do not need help or have unclear or negative perceptions of rehabilitation and support. ${ }^{4}$

\section{APPROACHES TO VISION REHABILITATION INTERVENTIONS}

The ideal approach to vision rehabilitation 


\section{"An effective support service for patients with vision loss must be holistic and encompass many different areas including emotional, informational, practical, and peer support."}

interventions is an area of ongoing research. Evidence is limited due to a lack of highquality research in this area, and though many different interventions have been studied there is not enough evidence in one single area to draw a strong conclusion. Rabiee $P$ et $a l^{1}$ reviewed communitybased rehabilitation services for adults and covered a variety of angles including function, mental health, and self-efficacy. The authors found that group-based intervention had the greatest support, with four systematic reviews finding them to improve function, self-efficacy, mood, and quality of life $e^{5-8}$ as it provides the opportunity for visually impaired people to meet, which can reduce feelings of social isolation and provide a platform for friendship and sharing of experiences.

\section{THE EMOTIONAL ASPECTS OF VISION LOSS}

Most interventions target functional aspects of visual loss rather than social and emotional aspects.' However, the need for more emotional support for visually impaired people is well documented as there is a high rate of depression, anxiety, and sleep disturbance in these patients.., 10 The diagnosis of vision loss can be incredibly difficult for patients to deal with. It has an impact on self-identity and what a person feels they can achieve. Emotional distress and social isolation is common before people have come to terms with their vision loss $^{11}$ and its negative impacts on quality of life are well documented as everyday activities such as reading, walking, driving, cooking, and working are impaired. ${ }^{12}$

Psychological adjustment is a key factor in the ability to cope with and compensate for vision impairment. ${ }^{12}$

\section{CONCLUSION}

An effective support service for patients with vision loss must be holistic and encompass many different areas including emotional, informational, practical, and peer support. ${ }^{2}$ Although informational and practical support is satisfactory, patients with visual impairment consistently report that they feel the need for more emotional support as vision loss has such a large impact on mental wellbeing, and that this area is often neglected by current services.

\section{Arthur Barrow,}

Foundation Year 2 Doctor, Birmingham City Hospital, Birmingham, West Midlands.

\section{Louise Ting,}

Foundation Year 2 Doctor, Birmingham City Hospital, Birmingham, West Midlands.

\section{Vijay Patel,}

Foundation Year 2 Doctor, Birmingham City Hospital, Birmingham, West Midlands.

\section{Provenance}

Freely submitted; externally peer reviewed.

DOI: https://doi.org/10.3399/bjgp18X697613

\section{ADDRESS FOR CORRESPONDENCE}

Arthur Barrow

Birmingham City Hospital, Dudley Road,

Birmingham B18 7QH, UK.

Email: arthur_barrowahotmail.co.uk

\section{REFERENCES}

1. Rabiee P, Parker G, Bernard S, Baxter K. Vision rehabilitation services: what is the evidence? Final report. University of York, 2015.

2. Maxwell M, Donaghy E, Woodhouse A, et al. The Living Better Project. 2008. https:// unw.mentalhealth.org.uk/sites/default/files/ the-living-better-report-pdf laccessed 5 Jun 2018).

3. Percival J. Whole system care and social inclusion of people with sight loss: implications of key research for policy and service development. J Integrated Care 2011; 19(5): 47-57.

4. Rees G, Saw CL, Lamoureux EL, Keeffe JE. Self-management programs for adults with low vision: needs and challenges. Patient Educ Couns 2007; 69(1-3): 39-46.

5. Binns AM, Bunce C, Dickinson C, et al. How effective is low vision service provision? A systematic review. Surv Ophthalmol 2012; 57(1): 34-65.

6. Hooper P, Jutai JW, Strong G, Russell-Minda E. Age-related macular degeneration and low-vision rehabilitation: a systematic review. Can J Ophthalmol 2008; 43(2): 180-187.

7. Lee L, Packer TL, Tang SH, Girdler S. Selfmanagement education programs for agerelated macular degeneration: a systematic review. Australas J Ageing 2008; 27(4): 170-176.

8. Rees G, Ponczek E, Hassell J, et al Psychological outcomes following interventions for people with low vision: a systematic review. Expert Rev Ophthalmol 2010; 5(3): 385-403.

9. Evans J, Fletcher A, Wormald R. Depression and anxiety in visually impaired older people. Ophthalmology 2007; 114(2): 283-288.

10. Burmedi D, Becker S, Heyl V, et al. Emotional and social consequences of age-related low vision. Vis Impair Res 2002; 4(1): 47-55.

11. King E, Gilson SEL, Peveler R. Psychosocial needs of elderly visually impaired patients: pilot study of patients' perspectives. Prim Care Ment Health 2006; 4: 185-197.

12. Kempen G, Ballemans J, Ranchor A, et al The impact of low vision on activities of daily living, symptoms of depression, feelings of anxiety and social support in communityliving older adults seeking vision rehabilitation services. Qual Life Res 2012; 21(8): 1405-1411. 